\title{
The effect of phenobarbital on rate of forgetting and proactive interference in delayed matching to sample
}

\author{
JANINE E. WATSON and K. GEOFFREY WHITE \\ University of Otago, Dunedin, New Zealand
}

\begin{abstract}
The barbiturate phenobarbital impairs the performance of nonhumans in delayed matchingto-sample procedures. In the present study, the performance of pigeons in a delayed matching-tosample task was examined as a function of dose level of intraperitoneal phenobarbital administration. Percent-correct matching accuracy decreased with increasing delay-interval duration to a greater extent under 20 - and $30-\mathrm{mg} / \mathrm{kg}$ doses of phenobarbital than for vehicle control and $10-\mathrm{mg} / \mathrm{kg}$ conditions. That is, phenobarbital accentuated rate of forgetting. Rate of forgetting was also assessed in terms of the rate parameter of negative exponential functions fitted to discriminability measures for different delay intervals, thus allowing a separation of memorial from attentional influences. Proactive interference was evident as a greater rate of forgetting for trials in which the sample stimulus to be remembered differed from that on the preceding trial, compared with trials in which the consecutive sample stimuli were the same. Increasing dose levels of phenobarbital attenuated proactive interference. Phenobarbital therefore impairs memorial function and limits the influence of information gained from previous trials in guiding or steering performance on the current trial.
\end{abstract}

It is now becoming accepted that certain anticonvulsant drugs prescribed for the control of epileptic seizures have undesirable side effects. One such widely used anticonvulsant is the barbiturate phenobarbital (Gibbs, Gibbs, Gibbs, Dikman, \& Hermann, 1982). Children with epilepsy who are prescribed phenobarbital may show increased hyperactivity, problems with sleep and school, difficulties on spatial-motor tasks, and impairments in intellectual and cognitive functioning (Trimble, Thompson, \& Corbett, 1982; Werry, 1988). Such side effects are a problem, especially given the implications that they have for the child's educational and social development (Stores, 1981).

In clinical studies using both adults and children, a wide variety of intellectual and cognitive functions has been assessed including general intelligence, attention, distractibility and impulsivity, perceptual-motor functioning, and reading and arithmetic ability (Werry, 1988). Increasingly, attention has focused on the effects of drugs on memory processes, and there is evidence from both clinical and animal studies that phenobarbital has an adverse effect on memory functioning. Lower scores on the standard clinical measures, the Wechsler Memory Scale and the Benton Visual Retention Test, are associated with

This research was supported by a grant from the New Zealand Neurological Foundation. We thank Norma Bartlett for assistance in manuscript preparation, Barry Dingwall and his team for technical assistance, and Fiona McPherson for assistance during the conduct of the research. $J$. Watson is now at the Department of Pediatrics, Arkansas Children's Hospital, Little Rock, AR 72202. Reprints may be obtained from K. G. White, Department of Psychology, University of Otago, Dunedin, New Zealand. higher blood plasma levels of phenobarbital (Trimble \& Thompson, 1981). In a study of the effects of phenobarbital on memory, MacLeod, DeKaban, and Hunt (1978) tested patients with moderate and high phenobarbital levels by using a scanning task and a letter-matching task. They found that short-term-memory scanning was significantly impaired when phenobarbital levels were high, but retrieval of information in long-term memory was not affected.

The results of animal studies using phenobarbital and other barbiturates support the findings of memory impairments reported in clinical studies. A procedure commonly used to study short-term memory in animals is the conditional discrimination procedure of delayed matching to sample (DMTS). In the DMTS procedure, a sample stimulus is presented and subsequently removed. After a short delay, or retention interval, comparison stimuli are presented, and the subject's task is to respond to the stimulus that matches the original sample stimulus. It is assumed that short-term memory is involved in DMTS performance, as information about the sample stimulus must be retained during the retention interval (McMillan, 1981; White \& Alsop, 1993). Impairments in DMTS performance with barbiturate administration have been reported in primates (Geller, Hartmann, \& Moran, 1983; Nicholson, Wright, \& Ferres, 1973; M. H. T. Roberts \& Bradley, 1967) and in pigeons (Berryman, Cumming, Nevin, \& Jarvik, 1964; McMillan, 1981).

Picker, White, and Poling (1985) reported typical findings regarding the effects of phenobarbital. Pigeons were taught a DMTS task with delay values of $0.5,1,2,4$, or $8 \mathrm{sec}$. The effects of five acute doses of phenobarbital ranging from 5 to $40 \mathrm{mg} / \mathrm{kg}$ were determined. For all 3 
subjects, phenobarbital produced large dose-dependent decreases in matching accuracy across all the delay values. Although the effect of phenobarbital in decreasing accuracy was largest at the shorter delay values, lower doses were required to reduce responding to chance levels at the 8-sec delay than at the shorter delay intervals. The accuracy-decreasing effect of phenobarbital was accompanied by a slight increase in the rate of responding, but the magnitude of this effect was not dose dependent and showed considerable variation across subjects. Despite the robust finding that phenobarbital disrupts delayed matchingto-sample performance, there has been relatively little interest in determining the locus of this effect.

One factor that has a marked effect on DMTS performance is proactive interference (W. A. Roberts, 1980; Wright, Urcuioli, \& Sands, 1986). For example, performance on any one trial may be influenced by events that occurred prior to the sample stimulus on that particular trial. Prior events will proactively interfere if they occasion a response contrary to the correct response on that particular trial. The main variables used to study proactive interference in DMTS are the length of the intertrial interval and the correspondence between stimulus events on consecutive trials. Edhouse and White (1988) suggested that intertrial interval influences attention to the sample stimulus, whereas intertrial correspondence of sample stimuli on consecutive trials influences rate of forgetting. The aim of the present study was to determine the effects of phenobarbital on proactive interference in a DMTS task in pigeons. We asked whether phenobarbital influenced rate of forgetting, and whether there is a change in the effect of intertrial correspondence on rate of forgetting as a result of phenobarbital administration.

\section{METHOD}

\section{Subjects}

Five adult homing pigeons with extensive experience in delayed matching-to-sample procedures were maintained at $80 \% \pm 15 \mathrm{~g}$ of their free-feeding weights. Experimental sessions were conducted daily unless a bird's weight was outside the prescribed range. Water and grit were always available in their home cages.

\section{Apparatus}

The interior of a sound-attenuating experimental chamber, $31 \mathrm{~cm}$ wide $\times 34 \mathrm{~cm}$ deep $\times 33 \mathrm{~cm}$ high, was painted matte black. An exhaust fan provided general masking noise. Three response keys were mounted on one wall, with a hopper opening below the center key. The three translucent response keys were $2.5 \mathrm{~cm}$ in diameter, $10 \mathrm{~cm}$ apart center to center, and $23 \mathrm{~cm}$ above the grid floor. Closure of microswitches mounted behind the keys required a force of at least $0.1 \mathrm{~N}$. There was no houselight. Each key could be illuminated red or green. There was no other illumination except when the hopper was illuminated with white light during 2-sec grain presentation. Experimental events were controlled and recorded by a PDP computer using SKED software, located in an adjacent room.

\section{Behavioral Procedure}

The subjects had extensive prior training, and because they showed a high level of accuracy at the beginning of the experiment, no pretraining was required. Daily experimental sessions consisted of 129 trials. Each trial began with the illumination of the center key with either red or green. The fifth peck darkened the key and initiated a delay that lasted for $0.2,1,4$, or $12 \mathrm{sec}$. During the delay the chamber was darkened, and responses were ineffective. The delay interval terminated with the onset of the comparison stimuli on the side keys (one red and one green). A single correct response darkened both keys, produced $2-\mathrm{sec}$ access to grain, and initiated an intertrial interval of $10 \mathrm{sec}$. Incorrect responses produced a 2-sec blackout followed by the 10 -sec intertrial interval.

Daily sessions of 129 trials included two blocks of 64 trials plus a "dummy" trial at the beginning of the first block. The dummy trial ensured the occurrence of a preceding trial for the first trial of the first block, but did not contribute to the analysis. The order of the red and green sample stimuli was randomized in blocks of 16 within each session, with the constraints described below. The left-right position of the correct comparison stimulus was balanced across types of trials, and each type of trial was tested an equal number of times with $0.2-, 1-, 4-$, and $12-\mathrm{sec}$ delays. That is, the different delays were mixed within sessions (White \& BunnellMcKenzie, 1985).

Each session included two types of intertrial sequence, defined by whether the sample stimuli (red or green) were the same or different on consecutive trials. When the samples were the same on consecutive trials, the comparison-stimulus location (whether red on left or red on right) was the same on consecutive trials for half the trials, and differed between consecutive trials on the other half. Similarly, when the samples differed on consecutive trials, comparison-stimulus location was either the same or different. Previous research has demonstrated that comparison-stimulus location is unimportant to the correspondence between consecutive trials, whereas the important factor is whether consecutive samples are the same or different (Edhouse \& White, 1988).

Forty sessions of baseline training in the above procedure were preceded by about 3 months of training in the same procedure, but with overall short delay intervals. As described below, drug and vehicle administration and additional baseline training were conducted over 89 sessions following the initial baseline training.

\section{Pharmacological Procedure}

Phenobarbital, obtained from commercial suppliers, was diluted to the required concentration with distilled water. The doses used in this study were 10,20 , and $30 \mathrm{mg} / \mathrm{kg}$. These doses were based on previous reports in which pigeons were used as subjects (McMillan, 1981; Picker et al., 1985). Each of the three doses and a vehicle control injection of distilled water (designated here as $0 \mathrm{mg} / \mathrm{kg}$ ) were administered to each of the subjects in a random order. Injections were given in a volume of $1 \mathrm{ml} / \mathrm{kg}$, intraperitoneally, $15 \mathrm{~min}$ prior to the start of the experimental session. Following $\mathbf{4 0}$ days of training in the procedure described above (baseline), the first injection was distilled water. Over the next 28 sessions, injections of vehicle, 10,20 , and $30 \mathrm{mg} / \mathrm{kg}$ preceded each of 2 individual sessions, and sessions with drug or vehicle were separated by 3 sessions of baseline training. The order of drug and vehicle sessions was $0,10,30,20,10,30,0,20$, for all the birds. Following a further 24 sessions of baseline training, drug or vehicle was administered before single sessions in the order $0,30,20,10$, with between 1 and 4 days of baseline training separating these sessions over a total of 11 days. Following a further 14 sessions of baseline, injections were administered before single sessions in the order $20,30,10,0$, with 2 or 3 baseline sessions separating the drugadministration sessions over a total of 12 sessions. By the end of the experiment, 4 sessions of training were completed under each dose level of the drug and vehicle control, distributed over 89 sessions since initial baseline training. 


\section{RESULTS}

\section{Percent Correct}

Total correct matching responses at each of the four delay intervals were summed over the four sessions conducted at each dose level $(0,10,20,30)$ for each bird (total of 128 trials per delay per dose level). The mean percent correct for each dose level as a function of delay interval is presented in Figure 1. These data were submitted to analysis of variance for repeated measures on the factors of dose level and delay interval. Figure 1 shows that matching accuracy decreased systematically with increasing delay $[F(3,12)=89.93, p<.001]$ and with increasing dose level $[F(3,12)=19.47, p<.001]$. There was also a significant interaction between delay and dose $[F(9,36)=2.56, p<.05]$.

The percentage of correct matching responses was high for the short delays in the vehicle control condition, decreasing to $67 \%$ at the 12 -sec delay. The percentage correct decreased with increasing drug dose, with performance levels for the $30-\mathrm{mg} / \mathrm{kg}$ condition at the long delays approaching chance (50\%). These data are consistent with the results of previous studies of the effects of phenobarbital on delayed matching-to-sample performance in pigeons (McMillan, 1981; Picker et al., 1985).

\section{Drug Effects on Proactive Interference}

For the following analysis the dependent measure used was discriminability, in order to avoid the potential problem of percent correct's being influenced by response bias. The bias-free discriminability measure, $\log d_{t}$, is identical to Luce's (1963) discriminability measure and has the same properties as $d^{\prime}$ from signal detection theory (Davison \& Tustin, 1978; White \& McKenzie, 1982). It is calculated as the logarithm (base 10) of the product of the ratios of correct to error $(c / e)$ responses following red and green $(\mathrm{r}, \mathrm{g})$ samples. That is, $\log d_{t}=0.5 \cdot \log \left(c_{\mathrm{r}} / e_{\mathrm{r}}\right)$ $\left(c_{\mathrm{g}} / e_{\mathrm{g}}\right)$. Measures of discriminability at time $t, \log d_{t}$, were calculated separately for trials in which the samples were

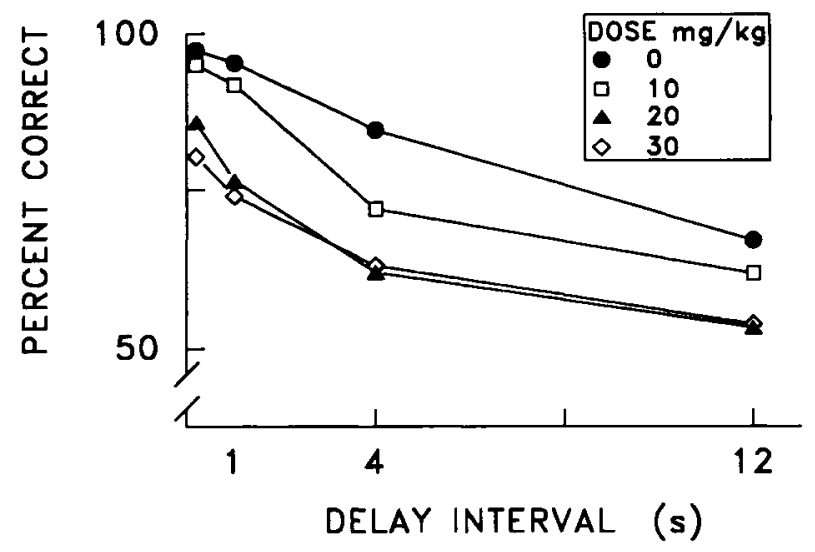

Figure 1. Mean percent-correct matching as a function of delay interval for vehicle control $(0-\mathrm{mg} / \mathrm{kg})$ and $10,20-$, or $30-\mathrm{mg} / \mathrm{kg}$ doses of phenobarbital. (Standard deviations averaged 0.091 of the means.)

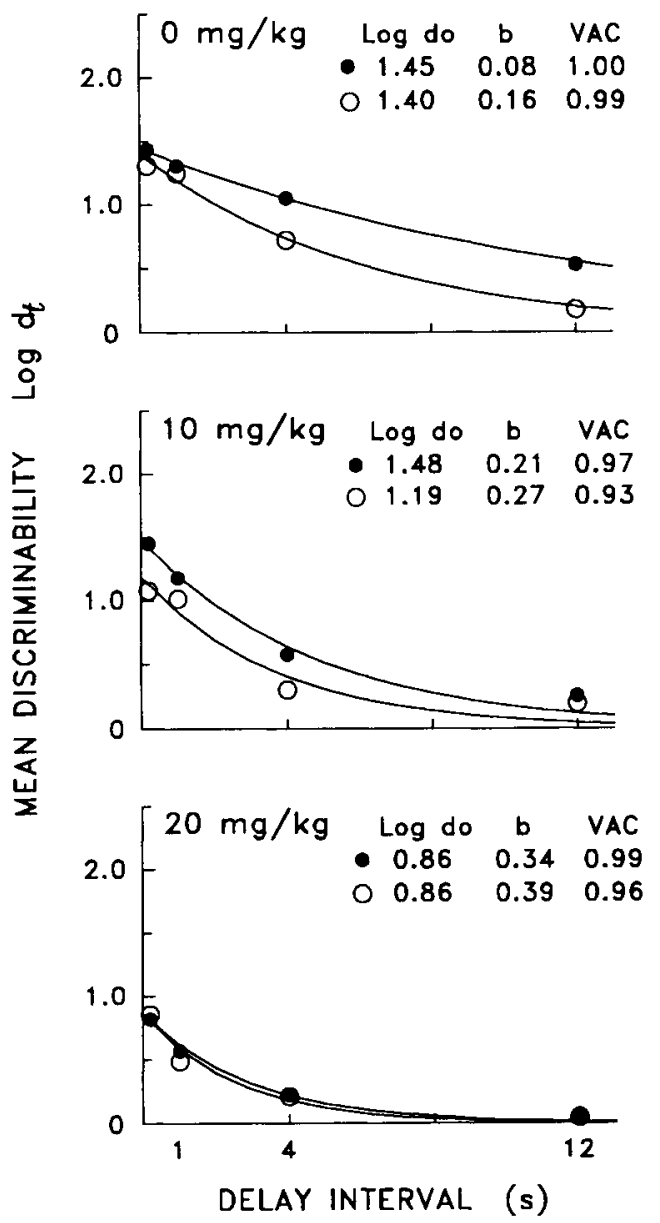

Figure 2. Mean discriminability as a function of delay interval for vehicle control and 10 - and $20-\mathrm{mg} / \mathrm{kg}$ doses of phenobarbital, separated for trials in which consecutive sample stimuli were the same (filled circles) or different (open circles). The smooth curves are negative exponential functions fitted to the mean discriminability values by a nonlinear least squares method. Values are given for the parameters for the best-fitting functions, initial discriminability $\left(\log d_{0}\right)$ and rate of forgetting (b), and variance accounted for (VAC).

either the same as or different from the samples on immediately preceding trials, at each delay and dose level for each bird. In a few instances in which the performance of individual birds was perfectly accurate at short delays, one error was added to the response totals in order to avoid indeterminate estimates of $\log d_{t}$. Although the discriminability values for the $30-\mathrm{mg} / \mathrm{kg}$ condition were very similar but smaller overall than those for the $20-\mathrm{mg} / \mathrm{kg}$ condition (cf. Figure 1), the data for the $30-\mathrm{mg} / \mathrm{kg}$ condition were not included in this analysis owing to incomplete sessions. That is, the full set of trials was not completed at each of the four delays for at least one of the $30-\mathrm{mg} / \mathrm{kg}$ sessions for 3 birds and, as a result, the relative contribution of the different trial types to the discriminability measure could not be determined.

Figure 2 shows measures of discriminability, $\log d_{t}$, averaged over birds and plotted as a function of delay for 
the vehicle control and the $10-$ and $20-\mathrm{mg} / \mathrm{kg}$ conditions. As with percent correct (Figure 1), discriminability decreased with increasing delay and increasing dose level. Proactive interference was manifested as lower discriminability when samples on consecutive trials differed than when they were the same. Proactive interference was greatest at longer delays and for the vehicle control condition. The difference in discriminability for same and different consecutive samples did not occur for the $20-\mathrm{mg} / \mathrm{kg}$ condition (or for the $30-\mathrm{mg} / \mathrm{kg}$ condition, notwithstanding incomplete data).

The proactive interference effect was quantified by fitting negative exponential functions to the discriminability data by a nonlinear least squares method. The negative exponential function, given by Equation 1, has two parameters, discriminability at zero delay, $\log d_{0}$, and rate of decrement in discriminability, $b$ (White, 1985):

$$
\log d_{t}=\log d_{0} \cdot \exp (-b t) \text {. }
$$

The advantage of Equation 1 in describing the data is that it yields two higher order measures of performance. Initial discriminability, $\log d_{0}$, may reflect the influence of attentional or encoding factors, and rate of decrement, $b$, may reflect memorial or retrieval factors and is interpreted as rate of forgetting (White, 1985). The two parameters are differentially influenced by various procedural factors and are independent (White, 1991). In particular, proactive interference resulting from the lack of intertrial correspondence is manifested as a difference in rate of forgetting, with larger values of $b$ for trials in which the sample of the preceding trial differs from the sample on the current trial than for trials in which the samples are the same across consecutive trials (Edhouse \& White, 1988).

Table 1 gives parameter values for best-fitting exponential functions to discriminability measures for individual birds. The fits were generally satisfactory, as shown by the high proportions of variance accounted for (VAC) and low mean squared error terms $\left(M S_{\mathrm{e}}\right)$. In the vehicle control condition $(0 \mathrm{mg} / \mathrm{kg})$, for each of the 5 birds, the rate of forgetting for trials in which the samples differed from those on the previous trial was about twice the value of the rate of forgetting when the samples across consecutive trials were the same. Proactive interference was therefore evident in individual data for vehicle control, consistent with previous studies (Edhouse \& White, 1988). For the $10-\mathrm{mg} / \mathrm{kg}$ condition, $b$ was larger for differentsamples trials for 4 out of 5 birds, but the difference was less marked. For the $20-\mathrm{mg} / \mathrm{kg}$ condition, the rate of forgetting on same-sample trials did not systematically differ from that on different-sample trials. That is, there was no proactive interference for the $20-\mathrm{mg} / \mathrm{kg}$ condition. Overall, the difference in $b$ between same- and differentsample trials was significant $[F(1,4)=11.96, p<.05]$ and the general increase in $b$ with increasing dose level was significant $[F(2,8)=6.71, p<.05]$. The significant interaction between same-different samples and dose level confirmed the presence of proactive interference in the vehicle control condition (shown as a rate-of-forgetting difference) and its disappearance with increasing doses of phenobarbital $[F(2,8)=4.82, p<.05]$.

Table 1 shows that initial discriminability, $\log d_{0}$, generally decreased with increasing dose level $[F(2,8)=$ $10.03, p<.01]$, but there was no consistent effect of same-different samples on $\log d_{0}[F(1,4)=3.34, p>$ .05]. The effect on $\log d_{0}$ of the interaction between same-different samples and dose level was not significant $[F(2,8)=1.03, p>.05]$. That is, proactive interference between consecutive trials was restricted to a difference in rate of forgetting, as concluded by Edhouse and White (1988).

The individual data are summarized by exponential functions fitted to the mean discriminability values in Figure 2. The parameter values for these functions, given in Figure 2, are consistent with those for individual data. Although $\log d_{0}$ decreases with increasing dose level, it

Table 1

Initial Discriminability $\left(\log d_{0}\right)$ and Rate of Forgetting $(b)$

for Best-Fitting Exponential Functions to Data for Individual Birds,

for Trials in Which Consecutive Samples Were the Same or Different

\begin{tabular}{|c|c|c|c|c|c|c|c|c|c|}
\hline \multirow[b]{2}{*}{ Bird } & \multirow{2}{*}{$\begin{array}{c}\text { Dose level } \\
(\mathrm{mg} / \mathrm{kg})\end{array}$} & \multicolumn{4}{|c|}{ Same Samples } & \multicolumn{4}{|c|}{ Different Samples } \\
\hline & & $\log d_{0}$ & $b$ & VAC & $M S_{\mathrm{e}}$ & $\log d_{0}$ & $b$ & VAC & $M S_{\mathrm{e}}$ \\
\hline D1 & $\begin{array}{r}0 \\
10 \\
20\end{array}$ & $\begin{array}{l}1.56 \\
1.44 \\
1.39\end{array}$ & $\begin{array}{l}.07 \\
.16 \\
.61\end{array}$ & $\begin{array}{l}.99 \\
.91 \\
.99\end{array}$ & $\begin{array}{l}.001 \\
.016 \\
.003\end{array}$ & $\begin{array}{l}1.57 \\
1.00 \\
1.24\end{array}$ & $\begin{array}{l}.16 \\
.31 \\
.47\end{array}$ & $\begin{array}{l}.98 \\
.80 \\
.99\end{array}$ & $\begin{array}{l}.005 \\
.027 \\
.003\end{array}$ \\
\hline D2 & $\begin{array}{r}0 \\
10 \\
20\end{array}$ & $\begin{array}{r}1.38 \\
1.51 \\
.73\end{array}$ & $\begin{array}{l}.17 \\
.33 \\
.50\end{array}$ & $\begin{array}{l}.93 \\
.99 \\
.89\end{array}$ & $\begin{array}{l}.015 \\
.004 \\
.006\end{array}$ & $\begin{array}{r}1.05 \\
.97 \\
.91\end{array}$ & $\begin{array}{l}.43 \\
.45 \\
.51\end{array}$ & $\begin{array}{l}.95 \\
.98 \\
.95\end{array}$ & $\begin{array}{l}.007 \\
.003 \\
.006\end{array}$ \\
\hline D3 & $\begin{array}{r}0 \\
10 \\
20\end{array}$ & $\begin{array}{r}1.54 \\
1.52 \\
.59\end{array}$ & $\begin{array}{l}.08 \\
.19 \\
.19\end{array}$ & $\begin{array}{l}.74 \\
.99 \\
.90\end{array}$ & $\begin{array}{l}.050 \\
.002 \\
.005\end{array}$ & $\begin{array}{r}1.42 \\
1.58 \\
.62\end{array}$ & $\begin{array}{l}.14 \\
.28 \\
.25\end{array}$ & $\begin{array}{l}.88 \\
.92 \\
.73\end{array}$ & $\begin{array}{l}.030 \\
.020 \\
.014\end{array}$ \\
\hline D4 & $\begin{array}{r}0 \\
10 \\
20\end{array}$ & $\begin{array}{r}1.36 \\
1.45 \\
.99\end{array}$ & $\begin{array}{l}.03 \\
.09 \\
.21\end{array}$ & $\begin{array}{l}.63 \\
.92 \\
.91\end{array}$ & $\begin{array}{l}.011 \\
.010 \\
.011\end{array}$ & $\begin{array}{r}1.54 \\
1.53 \\
.95\end{array}$ & $\begin{array}{l}.08 \\
.20 \\
.15\end{array}$ & $\begin{array}{l}.90 \\
.89 \\
.81\end{array}$ & $\begin{array}{l}.016 \\
.031 \\
.017\end{array}$ \\
\hline D5 & $\begin{array}{r}0 \\
10 \\
20\end{array}$ & $\begin{array}{r}1.51 \\
1.41 \\
.65\end{array}$ & $\begin{array}{l}.14 \\
.26 \\
.28\end{array}$ & $\begin{array}{l}.99 \\
.96 \\
.95\end{array}$ & $\begin{array}{l}.003 \\
.011 \\
.003\end{array}$ & $\begin{array}{r}1.65 \\
.94 \\
.44\end{array}$ & $\begin{array}{l}.30 \\
.24 \\
.28\end{array}$ & $\begin{array}{r}.99 \\
.93 \\
1.00\end{array}$ & $\begin{array}{l}.005 \\
.007 \\
.000\end{array}$ \\
\hline
\end{tabular}

Note-VAC $=$ variance accounted for $; M S_{c}=$ mean squared error. 
does not differ between same-sample and different-sample trials. Rate of forgetting increases with increasing dose level, and differs for same-sample and different-sample trials at $0 \mathrm{mg} / \mathrm{kg}$ but not at $20 \mathrm{mg} / \mathrm{kg}$. Rate of forgetting is therefore accentuated and proactive interference is attenuated by increasing doses of phenobarbital.

\section{DISCUSSION}

The present data show that increasing dose levels of phenobarbital reduced matching accuracy by pigeons in the delayed matching-to-sample procedure. The extent of this reduction was greater at longer retention intervals (as shown by the significant interaction between delay and dose), consistent with an increase in the rate of forgetting. Rate of forgetting was quantified in terms of the parameter $b$ of the negative exponential function fitted to the discriminability data. There was a significant increase in the rate-of-forgetting parameter with increasing dose levels of phenobarbital. We conclude, therefore, that phenobarbital has a detrimental effect on memorial function.

The conclusion that phenobarbital impairs memory accuracy is consistent with the results of previous studies in which pigeons performed delayed matching to sample. In the studies reported by McMillan (1981) and Picker et al. (1985), percent-correct matching decreased with increasing dose levels of phenobarbital and with increasing delay-interval duration in a manner similar to that reported in the present study. The first novel contribution of the present study was the demonstration that rate of forgetting was increased by phenobarbital. Additionally, there was an overall detrimental effect of phenobarbital on initial discriminability, as measured by the $\log d_{0}$ parameter. Either effect is consistent with a change in percent correct, and it was difficult to distinguish which of the two characteristics of the forgetting functions was influenced by phenobarbital from the percent-correct measures reported in the earlier studies. The advantage of quantifying the forgetting function by fitting negative exponentials to the discriminability measures is that values are obtained for the two parameters, $\log d_{0}$ and $b$ (White, 1985). Although these parameters are mathematically and empirically independent (White, 1991), both were influenced by phenobarbital in the present study. The influence on rate of forgetting $(b)$ confirms that phenobarbital is detrimental to memorial function. But in addition, the influence on initial discriminability, $\log d_{0}$, suggests that attentional processes or processes involved in the perceptibility of the sample stimuli are also disadvantaged by the drug.

Quantification of the forgetting function in terms of the negative exponential proved useful in previous studies in determining the effects on the two parameters characterizing memory performance. Watson and Blampied (1989) showed that the dose-dependent decrease in matching accuracy by pigeons caused by the phenothiazine chlorpromazine was due to a decrease in initial discriminability and also to an increase in the rate of forgetting. Melia,
Koob, and Ehlers (1990) showed that ethanol increased rate of forgetting without impairing initial discriminability in a similar task. Kirk, White, and McNaughton (1988) demonstrated that the reduction in matching accuracy by rats in an auditory delayed matching-to-sample task, produced by the anticholinergic scopolamine, was due to a decrease in initial discriminability only. Using the same procedure as that reported by Kirk et al. (1988), Tan, Kirk, Abraham, and McNaughton (1990) showed that chlordiazepoxide reduced initial discriminability, but not rate of forgetting. Quantification of the forgetting function therefore shows that some drugs influence both attentional and memorial processes, some influence only attention or overall performance, and others influence primarily the memorial process. When rate of forgetting is increased, as with phenobarbital in the present study, it can be concluded that some aspect of memorial function is clearly being affected. Clinical use of the barbiturate is therefore questionable when it may have implications for the educational development of children (cf. Werry, 1988).

The second novel contribution of the present study is the demonstration of an attenuating effect of phenobarbital on proactive interference. The type of proactive interference influenced is a "local" effect in which matching is less accurate when the sample to be remembered on the current trial differs from that on the preceding trial (Edhouse \& White, 1988). This local proactive interference is manifested as a difference in rate of forgetting $(b)$ but not initial discriminability $\left(\log d_{0}\right)$. The present data confirmed this distinction in that there was a statistically significant effect of whether samples on consecutive trials were the same or different on rate of forgetting, but not initial discriminability. In that local proactive interference is a rate-of-forgetting effect, the result that phenobarbital attenuates local proactive interference offers confirmation that phenobarbital influences memorial function. The attenuation of proactive interference by phenobarbital is a plausible result when it is considered that proactive interference relies on the persistence of memory for events on the previous trial through the current trial (Wright et al., 1986). The drug therefore limits the influence of information gained from previous trials in guiding or steering performance on the current trial.

\section{REFERENCES}

Berryman, R., Cumming, W. W., Nevin, J. A., \& Jarvik, M. E. (1964). Effects of sodium pentobarbital on complex operant discriminations. Psychopharmacologia, 6, 388-398.

Davison, M. C., \& Tustin, R. D. (1978). The relation between the generalized matching law and signal detection theory. Journal of the Experimental Analysis of Behavior, 29, 331-336.

Edhouse, W. V., \& WhITE, K. G. (1988). Sources of proactive interference in animal memory. Journal of Experimental Psychology: Animal Behavior Processes, 14, 56-71.

Geller, I., Hartmann, R. J., \& Moran, E. (1983). Phenobarbital and d-amphetamine effects on discrimination performance of rats and juvenile baboons. Pharmacology, Biochemistry \& Behavior, 18, 107-113. 
Gibbs, E. L., Gibbs, T. J., Gibbs, F. A., Dikman, S., \& Hermann, B. P. (1982). Antiepilepsy drugs. In S. E. Breuning \& A. Poling (Eds.), Drugs and mental retardation (pp. 268-329). Springfield, IL: Charies C Thomas.

Kirk, R. C., White, K. G., \& McNaughton, N. (1988). Low dose scopolamine affects discriminability but not rate of forgetting in delayed conditional discrimination. Psychopharmacology, 96, 541-546.

LuCE, R. D. (1963). Detection and recognition. In R. D. Luce, R. R. Bush, \& E. Galanter (Eds.), Handbook of mathematical psychology (Vol. 1, pp. 103-189). New York: Wiley.

Macleod, C. M., DeKaban, A. S., \& HunT, E. (1978). Memory impairment in epileptic patients: Selective effects of phenobarbitone concentration. Science, 202, 1102-1104.

McMillan, D. E. (1981). Effects of chemicals on delayed matching behavior in pigeons: I. Acute effects of drugs. Neurotoxicology, 2, 485-498.

Melia, K. F., Коов, G. F., \& Ehlers, C. L. (1990). Ethanol effects on delayed spatial matching as modeled by a negative exponential forgetting function. Psychopharmacology, 102, 391-398.

Nicholson, A. N., Wright, C. M., Ferres, H. M. (1973). Impaired performance on delayed matching in monkeys by heptabarbitone, pentobarbitone sodium and quinalbarbitone sodium. Neuropharmacology, 12, 311-317.

Picker, M., White, W., \& Poling, A. (1985). Effects of phenobarbital, clonazepam, valproic acid, ethosuximide and phenytoin on the delayed matching-to-sample performance of pigeons. Psychopharmacology, 86, 494-498.

RoberTs, M. H. T., \& BradLey, P. B. (1967). Studies on the effects of drugs on performance of a delayed discrimination. Physiology \& Behavior, 2, 389-397.

Roberts, W. A. (1980). Distribution of trials and intertrial retention in delayed matching to sample with pigeons. Journal of Experimental Psychology: Animal Behavior Processes, 6, 217-237.

STORES, G. (1981). Memory impairment in children with epilepsy. Acta Neurologica Scandinavica, 64 (Suppl. 89), 21-27.

Tan, S., Kirk, R. C., Abraham, W. C., \& McNaughton, N. (1990). Chlordiazepoxide reduces discriminability but not rate of forgetting in delayed conditional discrimination. Psychopharmacology, 101, 550-554.
Trimble, M. R., Thompson, P., \& Corbett, J. (1982). Anticonvulsant drugs, cognitive function, and behavior. In M. Sandler (Ed.), Psychopharmacology of anticonvulsants (pp. 106-121). Oxford: Oxford University Press.

Trimble, M. R., \& ThOMPSon, P. J. (1981). Memory, anticonvulsant drugs and seizures. Acta Neurologica Scandinavica, 64 (Suppl. 89), 31-39.

WATSON, J. E., \& BlAMPIED, N. M. (1989). Quantification of the effects of chlorpromazine on delayed matching to sample in pigeons. Journal of the Experimental Analysis of Behavior, 51, 317-328.

WERRY, J. W. (1988). Drugs, learning, and cognitive function in children: An update. Journal of Child Psychology \& Psychiatry, 29, 129-141.

WHITE, K. G. (1985). Characteristics of forgetting functions in delayed matching-to-sample. Journal of the Experimental Analysis of Behavior, 44, 15-34.

White, K. G. (1991). Psychophysics of direct remembering. In M. L. Commons, J. A. Nevin, \& M. C. Davison (Eds.), Signal detection: Mechanisms, models, and applications (pp. 221-237). Hillsdale, NJ Erlbaum.

White, K. G., \& Alsop, B. A. (1993). Cognition in birds. In A. Sahgal (Ed.), Behavioural neuroscience: A practical approach (pp. 137147). Oxford: Oxford University Press.

White, K. G., \& Bunnell-McKenzie, J. (1985). Potentiation of delayed matching with variable delays. Animal Learning \& Behavior, 13, 397-402.

White, K. G., \& McKenzIE, J. (1982). Delayed stimulus control: Recall for single and relational stimuli. Joumal of the Experimental Analysis of Behavior, 38, 305-312.

Wright, A. A., Urcuioli, P. J., \& SANDS, S. F. (1986). Proactive interference in animal memory. In D. F. Kendrick, M. E. Rilling, \& M. R. Denny (Eds.), Theories of animal memory (pp. 101-125). Hillsdale, NJ: Erlbaum.

(Manuscript received May 24, 1993; revision accepted for publication August 4, 1993.) 